\title{
Frequency of Rapid Growing Mycobacteria among Tuberculosis Suspected Patients in Basra- Iraq
}

\author{
Amin A. Al-Sulami ${ }^{1}$, Asaad Al-Taee ${ }^{2 *}$ and Zainab A. Hasan ${ }^{1}$ \\ ${ }^{1}$ College Education for Pure Science, University of Basra, Basra, Iraq
}

${ }^{2}$ Marine Science Center, University of Basra, Basra, Iraq

*Corresponding author: Asaad Al-Taee, College Education for Pure Science, University of Basrah, Basra, 61001, Iraq, Tel: 009647801405715; E-mail: amraltaee@yahoo.com

Received date: February 28, 2016; Accepted date: April 13, 2016; Published date: April 18, 2016

Copyright: (c) 2016 Al-Sulami AA, et al. This is an open-access article distributed under the terms of the Creative Commons Attribution License, which permits unrestricted use, distribution and reproduction in any medium, provided the original author and source are credited.

\begin{abstract}
Objective: The purpose of this study was to estimate the frequency of rapid growing mycobacteria among tuberculosis suspected patients in Basra governorate and study their resistance to drugs.

Methods: A total of 150 sputum samples were obtained from 150 suspected patients who attended the Advisory Clinic for Chest Diseases and Respiratory (ACCDR) in the Basra Governorate from 01/03/2013 to 1/02/2014. Smears were stained with the Ziehl Neelsen technique and specimens were inoculated on Lowenstein Jensen medium, Identification to species level was achieved on the basis of the growth characteristics, pigment production and conventional biochemical tests. Drug susceptibility was tested to rifampicin, ethambutol, pyrazinamide, isoniazid, and streptomycin using the proportional method.
\end{abstract}

Results: From 150 sputum samples, 23 isolates were Mycobacterium tuberculosis (MTB) (15.33\%) and 16 $(10.66 \%)$ were nontuberculous mycobacteria, seven isolates of them $(43.75 \%), 2$ males and 5 females, mean age 40 years, were identified using biochemical tests as rapid growing mycobacteria of which $4(25 \%)$ as M. chelonae, 2 $(12.5 \%) M$. abscessus and $1(6.2 \%) M$. smegmatis. In addition to that, the bacteria were successfully differentiated by Duplex-PCR, as MTB and NTM based on amplification of rpoB gene sequences. Sequencing of 165 rDNA showed matching with 6 biochemically identified ones, and one of the $4 M$. chelonae was $M$. chitae.

Drug susceptibility testing showed that one $M$. abscessus isolate appeared to be resistant to all antibiotics (TDR), while two isolates of $M$. chelonae showed resistance to ethambutol and rifampicin, while $M$. smegmatis showed weak resistance to pyrazinamide and resistance to rifampicin. Also, all isolates of $M$. chelonae were sensitive to pyrazinamide, isoniazid and streptomycin.

Conclusion: It appears that the rapidly growing mycobacteria represents a high frequency, among nontuberculosis detected patients, which requires phenotypical and genotypical confirmation on a follow-up, along with the examination of patterns of sensitivity. Implementing Duplex-PCR proved to be decisive for differentiating NTM from MTB.

Keywords: Rapid growing mycobacteria; Non tuberculosis mycobacterium; Suspected tuberculosis patients; TB; Antimicrobial susceptibility testing

\section{Introduction}

Non-tuberculousis mycobacteria (NTM) especially rapid growing mycobacteria (RGM) are environmental opportunistic pathogens and their role in human disease is increasingly recognized. In addition, several studies indicate that humans can be infected by NTM from various environmental sources, especially soil and water $[1,2]$.

Runyon classified these organisms as rapidly growing mycobacteria as they can produce mature colonies on agar plates within 7 days, while slowly growing mycobacteria need several more days to grow $[3,4]$.
Identification of rapidly growing mycobacteria is important for clinical and epidemiological studies because of their spread worldwide [2].

Although a system of national disease surveillance, as exists for Mycobacterium tuberculosis in developed countries, has not been implemented, infections caused by rapidly growing mycobacteria have been increasingly reported in recent years [5-7].

These rapidly growing organisms have been associated with a wide range of clinical syndromes in both immunocompetent and immunocompromised hosts, ranging from mild, such as infections of skin and soft tissue, to more serious disorders, including osteomyelitis, and lymph node, respiratory tract, bloodstream infections and disseminated infection $[6,8]$.

The differences in susceptibility patterns of species and resistance to first line antituberculosis drugs create challenges in the approach to treatment of these organisms [9]. 
This study is focused on the isolation and identification of rapidly growing mycobacteria from tuberculosis suspected patients, and testing their drug susceptibility because of their emerging importance in both sporadic infection and outbreak settings.

\section{Materials and Methods}

\section{Sample collection}

A total of 150 sputum samples were obtained from 150 patients admitted to the ACCDR, during a one year period "March 2013 to February 2014".

All sputa were collected in sterile, screw cap containers. The expectorated sputum was taken by asking the patient to cough deeply into the container, followed by immediate screwing off the cap. Samples were transported to the laboratory within two hours and processed immediately or refrigerated at $4^{\circ} \mathrm{C}$ as soon as possible [10].

\section{Microbiological examination}

The specimens were processed on the same day for microscopy and culture using standard procedures [11]. Smears were stained with the Ziehl Neelsen (ZN) technique. Specimens were inoculated onto Lowenstein Jensen (LJ) medium, after decontamination procedures and concentration, and then incubated at $37^{\circ} \mathrm{C}$. Cultures were examined every day for a week and then once a week for eight weeks. Isolates obtained weekly were confirmed as acid-fast bacilli by $\mathrm{ZN}$ staining.

Identification to species level was achieved on the basis of the growth characteristics, including growth in less than 7 days, growth at $37^{\circ} \mathrm{C}$, growth in the presence of $\mathrm{NaCl} 5 \%$, pigment production, Niacin production, pyrazinamidase, urease, nitrate reduction test, catalase test, heat-stable catalase $\left(\mathrm{pH} 7,68^{\circ} \mathrm{C}\right)$, Tween 80 hydrolysis, growth on MacConkey agar, arylsulfatase test, and colony morphology.

\section{Genetic identification}

DNA was extracted by DNA PrepMate-M (Bioneer) according to the manufacture's instructions and DNA was detected on agarose gel electrophoresis [12]. 16S rDNA sequencing was done in Nicem company (USA) and Macrogen company (Korea).

\section{Duplex PCR: RNA polymerase gene (rpoB) primers}

The isolates were subjected to identification by using Duplex PCR (two pairs of primers) in order to amplify rpoB gene which is listed in Table 1.

\begin{tabular}{|c|c|c|c|}
\hline Gene & $\begin{array}{l}\text { Primer } \\
\text { type }\end{array}$ & Primer sequence $\left(5^{\prime}-3^{\prime}\right)$ & $\begin{array}{l}\text { Size of } \\
\text { product }\end{array}$ \\
\hline \multirow{3}{*}{$\begin{array}{l}\text { rpoB } \\
\text { gene }\end{array}$} & Tbc 1F & $\begin{array}{l}\text { 5'- } \\
\text { CGTACGGTCGGCGAGCTGATCCAA } \\
-3^{\prime}\end{array}$ & \multirow{2}{*}{$235 \mathrm{bp}$} \\
\hline & TbcR5 R & $\begin{array}{l}\text { 5'- } \\
\text { CCACCAGTCGGCGCTTGTGGGTC } \\
\text { AA-3' }\end{array}$ & \\
\hline & M5 F & $\begin{array}{l}\text { 5'- } \\
\text { GGAGCGGATGACCACCCAGGACG } \\
\text { TC-3' }\end{array}$ & $136 \mathrm{bp}$ \\
\hline
\end{tabular}

\begin{tabular}{|l|l|l|l|}
\hline RM3 R & $\begin{array}{l}\text { 5'- } \\
\text { CAGCGGGTTGTTCTGGTCCATGAA } \\
\text { C-3' }\end{array}$ & \\
\hline
\end{tabular}

Table 1: rpoB gene primers.

\section{Thermal cycling condition}

The PCR method for amplifying the rpoB gene was conducted as reported by Singh et al. [13] (Table 2).

\begin{tabular}{|l|l|l|l|}
\hline Steps & Temperature & Time & No. of cycles \\
\hline Initial denaturation & $95^{\circ} \mathrm{C}$ & $5 \mathrm{~min}$ & 1 \\
\hline Denaturation & $94^{\circ} \mathrm{C}$ & $20 \mathrm{Sec}$ & \\
\hline Annealing & $55^{\circ} \mathrm{C}$ & $20 \mathrm{SeC}$ & 40 \\
\hline Extension & $72^{\circ} \mathrm{C}$ & $40 \mathrm{Sec}$ & \\
\hline Final extension & $72^{\circ} \mathrm{C}$ & 5 min & 1 \\
\hline TM = Melting temperature, $\mathrm{TA}=$ Annealing temperature & \\
\hline
\end{tabular}

Table 2: Program used in PCR amplification for rpoB gene.

\section{Drug susceptibility tests}

The in vitro antimicrobial susceptibility of these RGM was performed according to the proportional method [14]. Five antibiotics were used as rifampicin $1 \mu \mathrm{g} / \mathrm{ml}$, ethambutol $2 \mu \mathrm{g} / \mathrm{ml}$, pyrazinamide $0.25 \mu \mathrm{g} / \mathrm{ml}$, isoniazid $0.2 \mu \mathrm{g} / \mathrm{ml}$, streptomycin $2 \mu \mathrm{g} / \mathrm{ml}$.

The results were read after three weeks of incubation at $35^{\circ} \mathrm{C}$. The isolate was recorded as resistant when growth in the critical concentration of the drug is more than $1 \%$ the growth of the Middlebrook 7H10 medium without antibiotic. When the case is opposite, the isolate is considered as susceptible. The resistance percent was calculated by the following Equation 1 [15]:

$\frac{\text { Number of colonies on the drug }}{\text { Number of colonies on the control }} * 100=\%$ resistance (1)

\section{Results}

Of one hundred fifty tuberculosis suspected patients, attended the ACCDR who were suffering from upper respiratory tract infections, twenty three isolates were MTB (15.33\%) and sixteen (10.66\%) were NTM, seven of them (43.75\%) were rapid growing mycobacteria, which included $4(25 \%)$ as $M$. chelonae, $2(12.5 \%) M$. abscessus and 1 (6.2\%) M. smegmatis (Figures 1 and 2) (Table 3). 
Citation: Al-Sulami AA, Al-Taee A, Hasan ZA (2016) Frequency of Rapid Growing Mycobacteria among Tuberculosis Suspected Patients in

Page 3 of 5

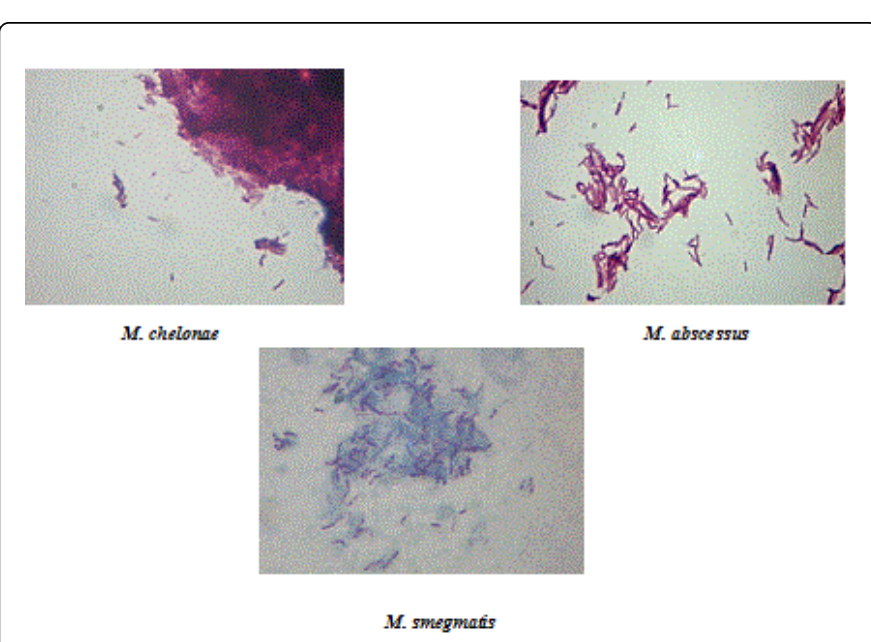

Figure 1: Direct examination of rapid growing mycobacteria on $\mathrm{ZN}$ stain under immersion oil (X100).

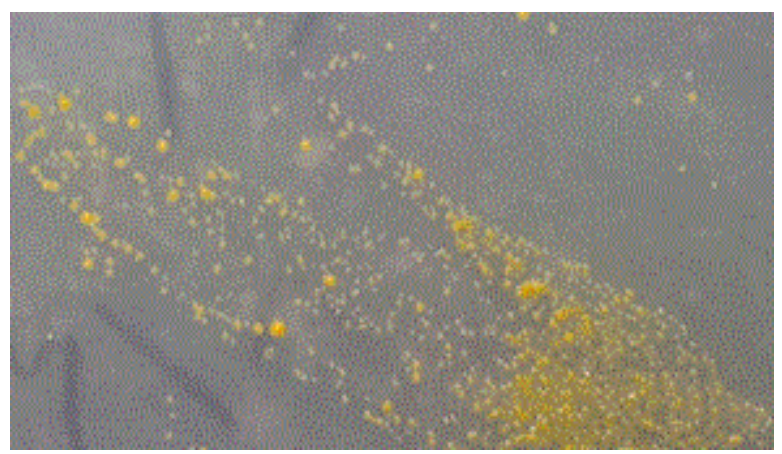

Figure 2: Rapid growing mycobacteria growth on the Middlebrook 7H10 medium.

\begin{tabular}{|l|l|l|l|}
\hline Tests & $\begin{array}{l}\text { M. chelonae } \\
\mathbf{4} \text { isolates }\end{array}$ & $\begin{array}{l}\text { M. abscessus } \\
\mathbf{2} \text { isolates }\end{array}$ & $\begin{array}{l}\text { M. smegmatis } \\
\mathbf{1} \text { isolate }\end{array}$ \\
\hline Growth in less than 7 days & + & + & + \\
\hline Growth at $37^{\circ} \mathrm{C}$ & + & + & + \\
\hline Photo reactive pigment & - & + & - \\
\hline Pigment in dark & - & - & + \\
\hline $\begin{array}{l}\text { Growth in presence of } \mathrm{NaCl} \\
5 \%\end{array}$ & + & + & + \\
\hline Growth on MacConkey agar & + & - & - \\
\hline Niacin production & - & - & - \\
\hline Nitrate reduction & + & - & + \\
\hline Arylsulfatase $(3$ days $)$ & + & + & - \\
\hline Tween 80 hydrolysis & + & - & + \\
\hline Heat stable catalase & - & - & - \\
\hline Pyrazinamidase & - & + & + \\
\hline
\end{tabular}

DNA amplification and duplex PCR: The isolates were identified by D-PCR method for differentiating between Mycobacterium tuberculosis (MTB) and NTM based on amplification of rpoB gene sequences. The results showed two bands, $235 \mathrm{bp}$ band for MTB and 136 bp band for NTM (Figure 4).

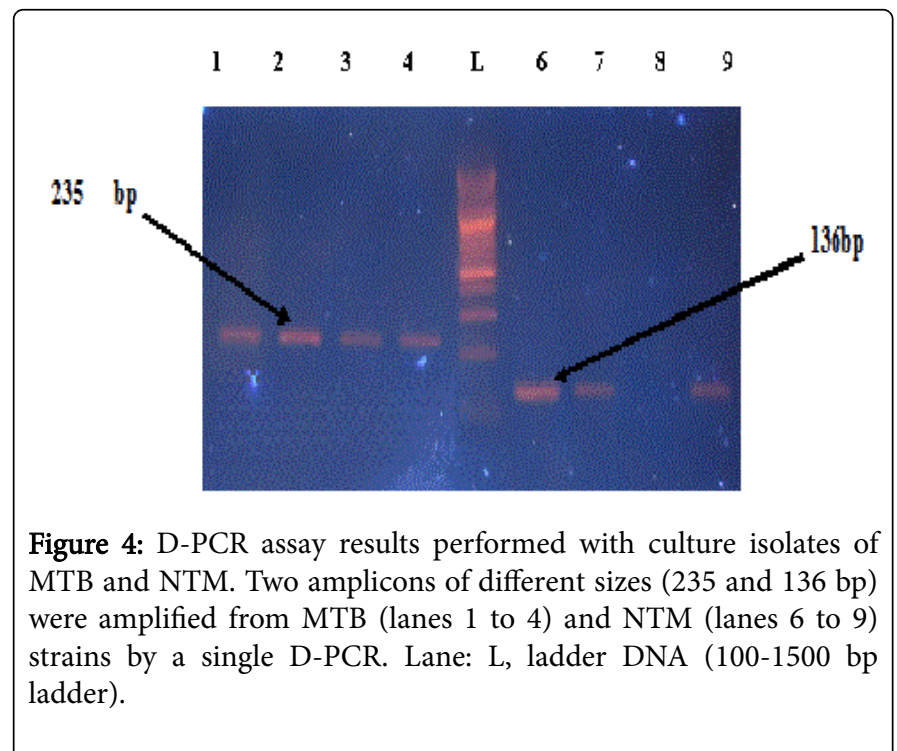

Sequencing for Universal 16S rDNA Gene: The isolates have been identified using $16 \mathrm{~S}$ rDNA sequencing, the results showed that 6 RGM 
matched with biochemical results, as follows: $M$. chelonae (n=3), $M$. abscessus $(\mathrm{n}=2)$ and $M$. smegmatis $(\mathrm{n}=1)$, while one M. chelonae did not match, and gave $M$. chitae.

Antibiotic susceptibility: The drug susceptibility results showed that, One $M$. chelonae isolate was resistant to EMB and one was MDR (RIF and EMB). M. smegmatis isolate was MDR (RIF and PZA), while one isolate of $M$. abscessus appeared to be resistant to all antibiotics tested. It was from a thirty year male, non smoker, with no previously documented lung disease, and lives in the poor socio-economic district. The rest isolates were sensitive (Table 4).

\begin{tabular}{|l|l|l|l|}
\hline \multirow{2}{*}{48} & Mycobacterial species & Antibiotics & Resistant percent \\
\hline \multirow{3}{*}{114} & M. chelonae & RIF & $95.70 \%$ \\
\cline { 3 - 4 } & M. chelonae & EMB & $4.20 \%$ \\
\hline \multirow{3}{*}{50} & \multirow{3}{*}{ M. abscessus } & RIF & $2 \%$ \\
\cline { 3 - 4 } & \multirow{3}{*}{110} & STR & $94 \%$ \\
\cline { 3 - 4 } & & EMB & $4 \%$ \\
\cline { 3 - 4 } & & INH & $10 \%$ \\
\cline { 3 - 4 } & \multirow{2}{*}{ M. smegmatis } & PZA & $8 \%$ \\
\hline & & RIF & $100 \%$ \\
\hline
\end{tabular}

Table 4: Resistance percentage of the RGM isolates against some antibiotics.

\section{Discussion}

Non-tuberculous mycobacterial infections are becoming increasingly common. Among them, the rapidly growing organisms such as Mycobacterium chelonae, Mycobacterium fortuitum and Mycobacterium abscessus are widespread in nature and in hospital environments [16].

The results showed that the rates of infection in Iraq are considered lower than the rates in the world based on previous studies [17-19].

To the best of our knowledge, this is the first study conducted in Iraq for the isolation and identification of NTM with human infection, a previous study was on environmental sites [1].

The results of the present study showed that, the prevalence of $M$. chelonae was $42.8 \%$, M. abscessus $28.5 \%$ and M. smegmatis $14.2 \%$ of RGM for all isolates from pulmonary samples. $M$. chelonae and $M$. abscessus have similar phenotypes and antimicrobial susceptibility profiles [20,21]. The profile of antibiotics of the RGM isolates appeared that, most isolates have the ability to resist one or more antimicrobial drugs (Table 4), One isolate of $M$. abscessus was resistant to all antimycobaterial drugs and this bacterium is deemed to be one of the most virulent and resistant species of rapidly growing mycobacteria. Many researchers found that, this bacterium is usually resistant to imipenem, ciprofloxacin, cotrimoxazole, linezolid, and doxycycline, but is susceptible only in vitro to amikacin and clarithromycin [22-25].

Depending on sputum smear only for diagnosis is not decisive as positive sputum smear may, in fact, due to an NTM that is then erroneously treated with standard anti-TB medications. As many NTM is resistant to first-line anti-TB medications, most of these cases would be considered failures, and subsequently treated with the second line regimen. On failure of the latter regimen, the patients are reported as chronic cases [26].

The mycobacterial cell wall functions as an efficient protective barrier and limits the entry of drug molecules to their cellular targets [27]. A major porin of M. smegmatis, MspA, forms a tetrameric complex with a single central pore [28]. Deletion of the porins MspA and $\mathrm{MspC}$ raised the resistance to $\beta$-lactam antibiotics without changing its $\beta$-lactamase activity. Hydrophilic fluoroquinolones such as norfloxacin, and chloramphenicol, diffuse through porins in mycobacteria [29].

The cell wall barrier alone is not enough to explain the intrinsic drug resistance of these bacteria. Drug efflux is a drug resistance mechanism contributed to intrinsic or acquired resistance in a wide range of bacteria [30]. M. smegmatis LfrA was the first multidrug efflux pump confirmed in mycobacteria [31]. It produces low-level resistance to fluoroquinolones and other toxic compounds such as ethidium bromide [31,32]. EfpA, Tap, and P55 are the three other major facilitator super family (MFS) pumps found in several mycobacterial species, and of these pumps, Tap and P55 are known to give low-level resistance to aminoglycosides and tetracyclines [33]. Mmr (a small multidrug resistance family (SMR) pump) and DrrAB (an ATP-binding cassette super family (ABC) exporter) were reported in MTB [34]. These exporters produce low-level resistance to certain antimicrobial agents [35]. Physiological adaptations appearing in the host can also lead to antibiotic tolerance [36].

\section{Conclusion}

An early identification of MTB and NTM is highly recommended, so that a correct antibiotic treatment can be initiated. The Duplex PCR proved to be the right differential technique. Concurrently, emerging drug resistance is indicated here by the appearance of one $M$. abscessus isolate resistant to all antimycobacterials pressing for more effective drugs.

Also, it is worthwhile to suggest the implementation of the monophasic - biphasic culture setup of tuberculosis broth and LJ agar for rapid recovery of MTB [1].

\section{References}

1. Al-Sulami AA, Al-Taee AM, Widaa Q (2012) Isolation and Identification of Mycobacterium avium complex and other non-tuberculosis mycobacteria from drinking water in Basra government, Iraq. East Mediter Health J 18: 274-278.

2. Rahideh S, Farnia P, Darbouy M (2014) Isolation and identification of rapidly growing mycobacteria from water and soil by PCR-RFLP method in Robat Karim. J Heal Hug 4: 321 - 329.

3. RUNYON EH (1959) Anonymous mycobacteria in pulmonary disease. Med Clin North Am 43: 273-290.

4. Runyon EH (1970) Identification of mycobacterial pathogens utilizing colony characteristics. Am J Clin Pathol 54: 578-586.

5. Sungkanuparph S, Sathapatayavongs B, Pracharktam R (2003) Infections with rapidly growing mycobacteria: report of 20 cases. Int J Infect Dis 7: 198-205.

6. De Groote MA, Huitt G (2006) Infections due to rapidly growing mycobacteria. Clin Infect Dis 42: 1756-1763. 
7. Chang CY, Tsay RW, Lin LC, Liu CE (2009) Venous catheter-associated bacteremia caused by rapidly growing mycobacteria at a medical center in central Taiwan. J Microbiol Immunol Infect 42: 343-350.

8. Redelman-Sidi G, Sepkowitz KA (2010) Rapidly growing mycobacteria infection in patients with cancer. Clin Infect Dis 51: 422-434.

9. Martín-Casabona N, Bahrmand AR, Bennedsen J, Thomsen VO, Curcio M, et al. (2004) Non-tuberculous mycobacteria: patterns of isolation. A multi-country retrospective survey. Int J Tuberc Lung Dis 8: 1186-1193.

10. SIREVA: Pan America health organization regional systems for vaccines (1998) Streptococcus pneumoniae and Haemophilus influenzae identification and susceptibility testing. Proceedings of the Institute Nacional de Saluda, Santa Fe de Bogota.

11. Koneman EW, Allen SD, Janda WM, Schreckenberger PC, Winn WC (1997) Colour atlas and textbook of diagnostic Microbiology. (5thedn) JB Lippincot Company, pp. 897- 906.

12. Sambrook J, Russell DW (2001) Molecular cloning - A laboratory manual. (3rdedn) Cold spring harbor laboratory press, Cold Spring Harbor, NY, USA

13. Singh P, Sharma V, Sharma N, Singh D, Kandpal J (2013) Evaluation of DPCR using the RNA polymerase gene (rpoB) primers for rapid differential identification of Mycobacterium tuberculosis complex and Nontuberculous Mycobacteria. Ann Bio Res 4: 45-48.

14. Canetti G, Froman S, Grosset J, Hauduroy P, Langerova M, et al. (1963) Mycobacteria: Laboratory Methods for Testing Drug Sensitivity and Resistance. Bull World Health Organ 29: 565-578.

15. Vestal AL (1975) Procedures for the isolation and identification of mycobacteria. U.S. Department of Health, Education and Welfare publication no. (CDC) 76-8230: 97-115, Center for Disease Control, Atlanta.

16. Sethi NK, Aggarwal PK, Duggal L, Sachar VP (2003) Mycobaterium chelonae infection following laparoscopic inguinal herniorrhaphy. JAPI 51: 81 .

17. Wallace RJ, Swenson JM, Silcox VA, Good RC, Tschen JA, et al. (1983) Spectrum of Disease Due to Rapidly Growing Mycobacteria. Clin Infect Dis 5: 657-679.

18. Jarand J, Levin A, Zhang L, Huitt G, Mitchell JD, et al. (2011) Clinical and Microbiologic Outcomes in Patients Receiving Treatment for Mycobacterium abscessus Pulmonary Disease. Clin Infect Dis 52: 565-571.

19. O'Driscoll C, Konjek J, Heym B, Fitzgibbon MM, Plant BJ, et al. (2016) Molecular epidemiology of Mycobacterium abscessus complex isolates in Ireland. J Cyst Fibros 15: 179-185.

20. El Helou G, Viola GM, Hachem R, Han XY, Raad II (2013) Rapidly growing mycobacterial bloodstream infections. Lancet Infect Dis 13: 166-174.

21. O'Driscoll C, Konjek J, Heym B, Fitzgibbon MM, Plant BJ, et al. (2016) Molecular epidemiology of Mycobacterium abscessus complex isolates in Ireland. J Cyst Fibros 15: 179-185.

22. Wallace RJ, Cook JL, Glassroth J, Griffith DE, Olivier KN, et al. (1997) The American Thoracic Society statement: diagnosis and treatment of disease caused by nontuberculous mycobacteria. Am J Respir Crit Care Med 156: S1-S25.

23. Griffith DE, Aksamit T, Brown-Elliott BA, Catanzaro A, Daley C, et al (2007) An official ATS/IDSA statement: diagnosis, treatment, and prevention of nontuberculous mycobacterial diseases. Am J Respir Crit Care Med 175: 367-416.

24. Han XY, Dé I, Jacobson KL (2007) Rapidly growing mycobacteria: clinical and microbiologic studies of 115 cases. Am J Clin Pathol 128: 612-621.

25. Esteban J, Martín-de-Hijas NZ, Fernandez AI, Fernandez-Roblas R, Gadea I; Madrid Study Group of Mycobacteria (2008) Epidemiology of infections due to nonpigmented rapidly growing mycobacteria diagnosed in an urban area. Eur J Clin Microbiol Infect Dis 27: 951-957.

26. Tabarsi P, Baghaei P, Farnia P, Mansouri N, Chitsaz E, et al. (2009) Nontuberculous mycobacteria among patients who are suspected for multidrug-resistant tuberculosis-need for earlier identification of nontuberculosis mycobacteria. Am J Med Sci 337: 182-184.

27. Brennan PJ, Nikaido H (1995) The envelope of mycobacteria. Annu Rev Biochem 64: 29-63.

28. Engelhardt H, Heinz C, Niederweis M (2002) A tetrameric porin limits the cell wall permeability of Mycobacterium smegmatis. J Biol Chem 277: 37567-37572.

29. Danilchanka O, Pavlenok M, Niederweis M (2008) Role of porins for uptake of antibiotics by Mycobacterium smegmatis. Antimicrob Agents Chemother 52: 3127-3134.

30. Li XZ, Nikaido H (2004) Efflux-mediated drug resistance in bacteria. Drugs 64: 159-204.

31. Takiff HE, Cimino M, Musso MC, Weisbrod T, Martinez R, et al. (1996) Efflux pump of the proton antiporter family confers low-level fluoroquinolone resistance in Mycobacterium smegmatis. Proc Natl Acad Sci USA 93: 362-366.

32. Liu J Takiff HE, Nikaido H (1996) Active efflux of fluoroquinolones in Mycobacterium smegmatis mediated by LfrA, a multidrug efflux pump. J Bacteriol 178: 3791-3795.

33. Silva PE, Bigi F, Santangelo MP, Romano MI, Martin, C, et al. (2001) Characterization of P55, a multidrug efflux pump in Mycobacterium bovis and Mycobacterium tuberculosis. Antimicrob. Agents Chemother 45: 800-804.

34. Choudhuri BS, Bhakta S, Barik R, Basu J, Kundu M, et al. (2002) Over expression and functional characterization of an ABC (ATP-binding cassette) transporter encoded by the genes drrA and $\operatorname{drrB}$ of Mycobacterium tuberculosis. Biochem J 367: 279-285.

35. De Rossi E, Branzoni M, Cantoni R, Milano A, Riccardi G, et al. (1998) $\mathrm{mmr}$, a Mycobacterium tuberculosis gene conferring resistance to small cationic dyes and inhibitors. J Bacteriol 180: 6068-6071.

36. Nguyen L, Pieters J (2009) Mycobacterial subversion of chemotherapeutic reagents and host defense tactics: challenges in tuberculosis drug development. Annu Rev Pharmacol Toxicol 49: 427-453. 